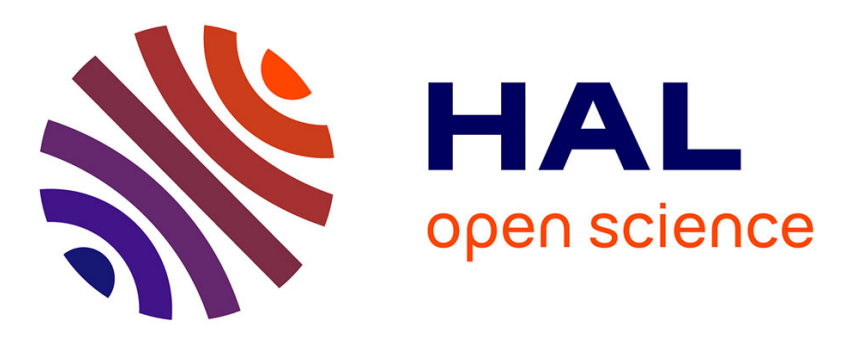

\title{
Analysis of the dynamic behaviour of magnetic gear with nonlinear modelling for large wind turbines
}

Melaine Desvaux, Roman Le Goff Latimier, Hamid Ben Ahmed, Bernard Multon, Stéphane Sire

\section{- To cite this version:}

Melaine Desvaux, Roman Le Goff Latimier, Hamid Ben Ahmed, Bernard Multon, Stéphane Sire. Analysis of the dynamic behaviour of magnetic gear with nonlinear modelling for large wind turbines. XXII International Conference on Electrical Machines (ICEM), 2016, Sep 2016, Lausanne, France. hal-01598093

\section{HAL Id: hal-01598093 \\ https://hal.science/hal-01598093}

Submitted on 29 Sep 2017

HAL is a multi-disciplinary open access archive for the deposit and dissemination of scientific research documents, whether they are published or not. The documents may come from teaching and research institutions in France or abroad, or from public or private research centers.
L'archive ouverte pluridisciplinaire HAL, est destinée au dépôt et à la diffusion de documents scientifiques de niveau recherche, publiés ou non, émanant des établissements d'enseignement et de recherche français ou étrangers, des laboratoires publics ou privés. 


\title{
Analysis of the Dynamic Behaviour of Magnetic Gear with Nonlinear Modelling for Large Wind Turbines
}

\author{
M. Desvaux, R. Le Goff Latimier, B. Multon, S. Sire, and H. Ben Ahmed
}

\begin{abstract}
This article deals with the dynamic behaviour of magnetic gear. This study is based on a nonlinear analytical model of magnetic gear which gives an analytical expression of the magnetic torque for a step disturbance. From this expression, various criteria will be defined in order to reach a good performance of the magnetic gear with step or sinusoidal disturbance. These results will be compared with a nonlinear simulation. Simulations show that it is possible to have, in a transitory regime, a load angle higher than the limit load angle maintaining a coupling between the low speed and the high speed rotor. Simulations will illustrate the importance of defining design rules based on the system application domain. A high power wind turbine (MW) example is proposed. In that case studies, loads generated by wind induce strong disturbances.
\end{abstract}

Index Terms-Damping factor, disturbance, dynamic, high torque application, load angle, magnetic gear, nonlinear simulation, operating range, transfer function, wind turbine.

\section{NOMENCLATURE}

$T_{G}:$ Maximum Gear torque $[\mathrm{Nm}]: T_{G}=\max \left(T_{l}\right)$

$T_{h}$ : High speed rotor magnetic torque [Nm]

$T_{\text {in }}$ : Input torque $[\mathrm{Nm}]$

$T_{l}$ : Low speed rotor magnetic torque $[\mathrm{Nm}]$

$T_{l 0}$ : Low speed magnetic torque after step disturbance [Nm]

$T_{\text {nom }}$ : Nominal torque of the wind turbine [Nm]

$T_{\text {out }}$ : Output torque [Nm]

$D_{\text {ext }}$ : External diameter of magnetic gear $[\mathrm{m}]$

$f_{\text {dist }}$ : Frequency of sinusoidal disturbance $[\mathrm{Hz}]$

$f_{h}$ : Fluid friction of the high speed rotor $[\mathrm{Nm} / \mathrm{rad} / \mathrm{s}]$

$f_{l}$ : Fluid friction of the low speed rotor $[\mathrm{Nm} / \mathrm{rad} / \mathrm{s}]$

$G_{r}:$ Gear ratio

$J_{h}:$ Inertia of high speed rotor $\left[\mathrm{kg} \cdot \mathrm{m}^{2}\right]$

$J_{l}$ : Inertia of low speed rotor $\left[\mathrm{kg} \cdot \mathrm{m}^{2}\right]$

$k$ : Ratio between nominal torque and maximum gear torque

$\mathrm{N}_{h}$ : Speed of high speed rotor [rpm]

$\mathrm{N}_{l}$ : Speed of high speed rotor [rpm]

$n_{s}$ : Number of ferromagnetic pole pieces

$O S_{\varphi}$ : Overshoot of the load angle for a step disturbance [\%]

$p_{h}$ : Number of magnetic pole pairs of high speed rotor

$p_{l}$ : Number of magnetic pole pairs of low speed rotor

This work was supported by the SATIE Laboratory, ENS Rennes, Université de Bretagne Loire and Université de Bretagne Occidentale through the provision of a Ph.D studentship.

Analysis Of The Dynamic Behaviour of Magnetic Gear with Nonlinear Modelling

M. Desvaux, R. Le Goff Latimier, H. Ben Ahmed and B. Multon belong to the Mechatronics Department of the ENS Rennes, SATIE Laboratory,
$\Delta T:$ Amplitude of torque step or sinusoidal disturbance [Nm]

$\Delta T_{l}$ : Torque overshoot on the low speed rotor [Nm]

$\omega_{0 h}$ : High speed rotor undamped resonance frequency $[\mathrm{rad} / \mathrm{s}]$

$\omega_{0 l}$ : Low speed rotor undamped resonance frequency $[\mathrm{rad} / \mathrm{s}]$

$\omega_{h}:$ Speed of high speed rotor $[\mathrm{rad} / \mathrm{s}]$

$\omega_{l}:$ Speed of low speed rotor $[\mathrm{rad} / \mathrm{s}]$

$\varphi$ : Load angle [rad]: $\varphi=p_{l} \cdot \theta_{l}+p_{h} \cdot \theta_{h}$

$\varphi_{0}$ : Final value of load angle (after step) [rad]

$\varphi_{i}$ : Initial value of load angle (before step) [rad]

$\theta_{h}$ : Angle of high speed rotor [rad]

$\theta_{h 0}$ : Angle of high speed rotor after step [rad]

$\theta_{h_{-} i}:$ Angle of high speed rotor before step [rad]

$\theta_{l}$ : Angle of low speed rotor [rad]

$\theta_{l 0}$ : Angle of high speed rotor after step [rad]

$\theta_{l_{-} i}:$ Angle of low speed rotor before step [rad]

$\xi_{h}$ : Damping factor of high speed rotor

$\xi_{l}$ : Damping factor of low speed rotor

\section{INTRODUCTION}

$\mathrm{F}$ OR wind turbine applications, mechanical gearboxes are frequently used in indirect drive (Fig.1a); this design allows a lower investment cost and a lower weight compared to direct drive designs (Fig.1b). However, failures of mechanical gearboxes and their induced production interruptions, which increase operating costs, are more frequently observed with indirect drive design [1].

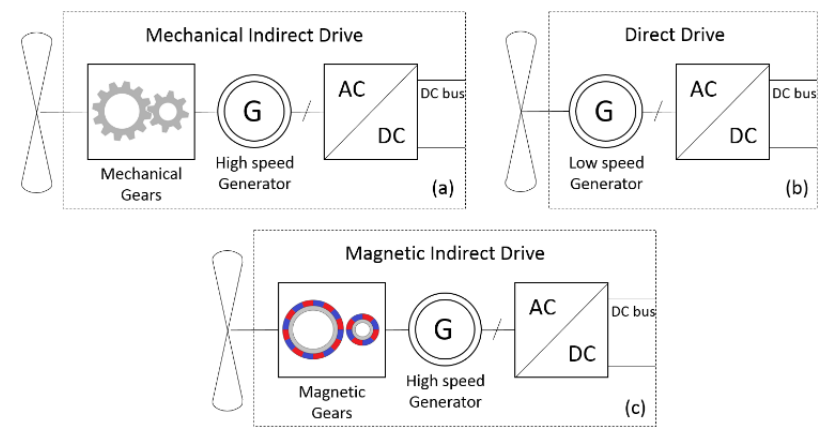

Fig. 1. Wind power conversion chains. (a) Mechanical indirect drive, (b) direct drive, and (c) magnetic indirect drive

Université de Bretagne Loire, CNRS, 35170 Bruz, France. (e-mail: Melaine.Desvaux@ens-rennes.fr)

S. Sire belongs to the Mechanical Engineering Department, Université de Bretagne Occidentale, FRE CNRS 3744, IDRL, 29238 Brest, France (e-mail: stephane.sire@univ-brest.fr) 
An interesting intermediate solution is to use a generator and combine it with magnetic gear (Fig.1c) to obtain a magnetic indirect drive. An attractive topology of magnetic gear (Fig.2) has been proposed by [2] in the early 2000s and used in different studies [3]-[5]. This magnetic gear includes a high speed rotor, a low speed rotor and fixed ferromagnetic pole pieces. This topology of magnetic gear potentially offers high performance and gives a hope of competitiveness compared to mechanical solutions [6] even for high torque applications (off-shore wind turbine for instance) [7]-[10]. In this article, only the case of fixed ferromagnetic pole pieces will be studied.

Their competitiveness must be evaluated in wind power context where the system is subjected to strong disturbances that can generate mechanical problems like resonance or loss of control of the magnetic gear after an overload. The uncoupling of the magnetic gear between two rotors due to overload is often described as an advantage (overload protection) but in the context of wind power, it can be dangerous. Indeed, when uncoupling occurs between rotors of the magnetic gear, the low speed rotor and the blades of the wind turbine are no longer subjected to torque breaking $\left(\bar{T}_{l}=\right.$ $\overline{T_{h}}=0$, where $\bar{T}_{l}$ and $\overline{T_{h}}$ are the average value of the low and the high speed rotor respectively) and can go faster and faster until damaging the wind power conversion chains. Some strategies have been proposed to counteract the uncoupling between rotors of the magnetic gear [11]-[12]. These strategies are based on servo control of magnetic gear but these solutions are not adapted to wind application due to the difficulty of the input torque pitch control.

This paper, therefore, aims at providing an analysis of the intrinsic dynamic characteristics of magnetic gear. It proposes some design criteria to make sizing relevant for its application domain without servo control. These criteria are described using analytical analysis and nonlinear simulations. This paper illustrates the importance of defining design rules based on the application domain. An example of application domain, applied to high power wind turbine, is proposed.

\section{NONLINEAR MAGNETO-MECHANICAL MODELLING OF MAGNETIC GEAR}

Magnetic gear [2] is composed of three rings:

- A high speed rotor ring with $\mathrm{p}_{\mathrm{h}}$ pole pairs of permanent magnets and a ferromagnetic yoke,

- A low speed rotor ring with $p_{1}$ pole pairs of permanent magnets and a ferromagnetic yoke,

- A fixed ferromagnetic ring with $\mathrm{n}_{\mathrm{s}}$ pole pieces between the two rotors (an example is given in Fig. 2 with $\mathrm{p}_{\mathrm{h}}=2, \mathrm{p}_{\mathrm{l}}=7, \mathrm{n}_{\mathrm{s}}=9$ ).

Each rotor generates in airgaps a wave of magneto-motive force. Ferromagnetic pole pieces aim to modulate the magnetic field in the two airgaps to obtain a common harmonic. The result is a magnetic torque with an average different from zero.
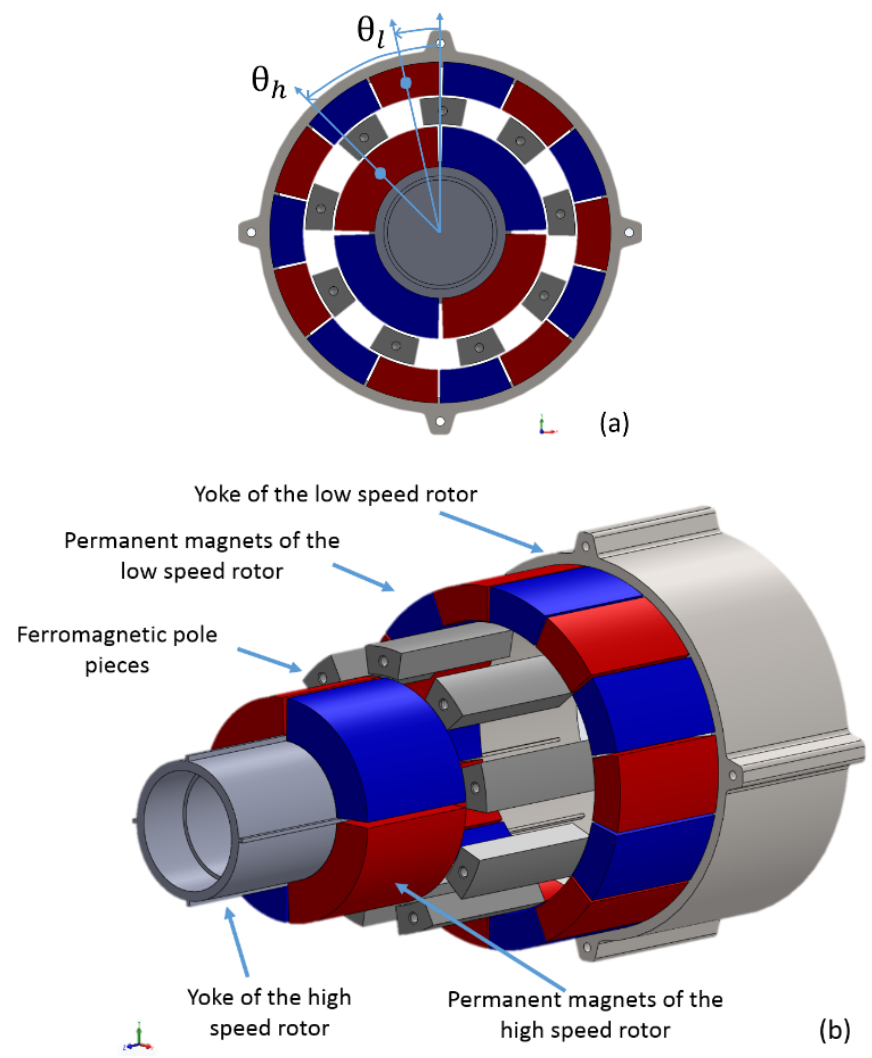

Fig. 2. Magnetic part of the magnetic gear (a) in side drawing (b) in exploded drawing (in this example $\mathrm{p}_{\mathrm{h}}=2, \mathrm{p}_{\mathrm{l}}=7, \mathrm{n}_{\mathrm{s}}=9$ )

The three rings parameters must follow the relation (1) and the gear ratio is given by (2) [3]. According to the studied configuration (fixed ferromagnetic pole pieces), the rotational speeds of the two rotors are opposite to each other (the gear ratio is negative). The coupling between the two rotors results in a magnetic torque whose expression is given by (3) with $T_{G}$ which depends to geometry and materials properties and without torque modulation for the two rotors:

$$
\begin{gathered}
p_{l}+p_{h}=n_{s} \\
G_{m}=-\frac{p_{l}}{p_{h}} \\
\left\{\begin{array}{c}
T_{l}=T_{G} \cdot \sin \left(p_{l} \cdot \theta_{l}+p_{h} \cdot \theta_{h}\right) \\
T_{h}=\frac{T_{G}}{G_{m}} \sin \left(p_{l} \cdot \theta_{l}+p_{h} \cdot \theta_{h}\right)
\end{array}\right.
\end{gathered}
$$

On the basis of this coupling, a block diagram of the magnetic gear can be proposed in Fig. 3:

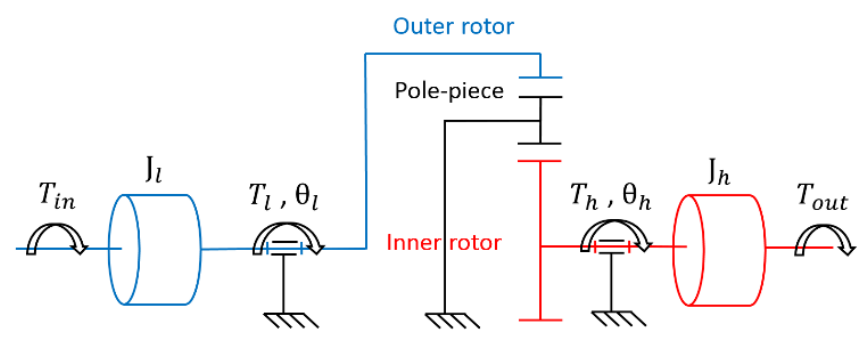

Fig. 3. Block diagram of the magnetic gear 
The dynamic equations are then deduced for the two rotors as reported in equations (4) and (5) in agreement with [12]. This dynamic equation has been solved in [12] with a linearization of the magnetic torque around a single position of the load angle. The scope of the present article is to carry out a modelling which takes into account the non-linearity of the magnetic torque.

$$
\begin{gathered}
\left\{\begin{array}{c}
J_{l} \frac{d^{2} \theta_{l}}{d t^{2}}=T_{\text {in }}-T_{l}-f_{l} \frac{d \theta_{l}}{d t} \\
J_{h} \frac{d^{2} \theta_{h}}{d t^{2}}=T_{h}-T_{\text {out }}-f_{h} \frac{d \theta_{h}}{d t}
\end{array}\right. \\
\left\{\begin{array}{c}
J_{l} \frac{d^{2} \theta_{l}}{d t^{2}}=T_{\text {in }}-T_{G} \cdot \sin \left(p_{l} \cdot \theta_{l}+p_{h} \cdot \theta_{h}\right)-f_{l} \frac{d \theta_{l}}{d t} \\
J_{h} \frac{d^{2} \theta_{h}}{d t^{2}}=\frac{T_{G}}{G_{m}} \sin \left(p_{l} \cdot \theta_{l}+p_{h} \cdot \theta_{h}\right)-T_{\text {out }}-f_{h} \frac{d \theta_{h}}{d t}
\end{array}\right.
\end{gathered}
$$

\section{ANALYTICAL EXPRESSION OF THE EVOLUTION OF THE MAGNETIC TORQUE FOR A STEP DISTURBANCE}

This section is dedicated to the analytical expression of the evolution of the magnetic torque for a step disturbance. This step can model, in a wind power context, a sudden increase of the wind, resulting in an increased $\Delta T$. The evolution of the torque will be analysed when the disturbance is applied to the low speed rotor (like in a wind turbine context) but can be transposed to the other case (disturbance on the high speed rotor). It is possible to describe two expressions of the evolution of the magnetic torque in function of the damping factor $\left(\xi_{l}\right)$. They correspond to the case where $\xi_{l}$ is less than one and to the case where $\xi_{l}$ is higher than one.

\section{A. Transfer function of the magnetic gear with load angle Taylor expansion}

In order to obtain an analytical expression of the dynamic behaviour of the system from (5), a Taylor expansion of the load angle is performed at the first order around all positions taken by the load angle. Equations (6) correspond to the Taylor expansion around $\varphi_{0}$.From the Laplace transform, it is possible to obtain the transfer function $\mathrm{H}_{l}(s)$ and $\mathrm{H}_{h}(s)$ available around $\varphi_{0}$ in (7) and identify the damping factor and the undamped resonance frequency for the two rotors, as shown in (8) and (9):

$$
\begin{aligned}
& \left\{\begin{array}{l}
J_{l} \frac{d^{2} \theta_{l}}{d t^{2}}=T_{\text {in }}-f_{l} \frac{d \theta_{l}}{d t} \\
\quad-T_{G}\left[\sin \left(\varphi_{0}\right)+\cos \left(\varphi_{0}\right)\left(p_{l} \theta_{l}+p_{h} \theta_{h}-\varphi_{0}\right)\right] \\
J_{h} \frac{d^{2} \theta_{h}}{d t^{2}}=-T_{\text {out }}-f_{h} \frac{d \theta_{h}}{d t} \\
\quad+\frac{T_{G}}{G_{m}}\left[\sin \left(\varphi_{0}\right)+\cos \left(\varphi_{0}\right)\left(p_{l} \theta_{l}+p_{h} \theta_{h}-\varphi_{0}\right)\right]
\end{array}\right. \\
& \left\{\begin{array}{c}
\frac{\theta_{l}(s)}{T_{\text {in }}(s)}=\mathrm{H}_{l}(p)=\frac{1}{J_{l} \cdot s^{2}+f_{l} . s+p_{l} \cdot T_{G} \cos \left(\varphi_{0}\right)} \\
\frac{\theta_{h}(s)}{T_{\text {out }}(s)}=\mathrm{H}_{h}(p)=\frac{1}{J_{h} . s^{2}+f_{h} . s-\frac{T_{G}}{G_{m}} \cdot p_{h} \cos \left(\varphi_{0}\right)}
\end{array}\right.
\end{aligned}
$$

$$
\begin{gathered}
\omega_{0 l}=\sqrt{\frac{p_{l} \cdot T_{G} \cos \left(\varphi_{0}\right)}{J_{l}}} \\
\xi_{l}=\frac{f_{l}}{2} \sqrt{\frac{1}{J_{l} \cdot p_{l} \cdot T_{G} \cos \left(\varphi_{0}\right)}} \\
\left\{\begin{array}{c}
\omega_{0 h}=\sqrt{\frac{p_{h} \cdot T_{G} \cos \left(\varphi_{0}\right)}{J_{h} \cdot\left|G_{m}\right|}} \\
\xi_{h}=\frac{f_{h}}{2} \sqrt{\frac{\left|G_{m}\right|}{J_{h} \cdot p_{h} \cdot T_{G} \cos \left(\varphi_{0}\right)}}
\end{array}\right.
\end{gathered}
$$

\section{B. Case where the damping factor is less than one}

In this case, the evolution of the position of low speed rotor $\left(\theta_{l}\right)$ valid for a small evolution of the load angle can be described by equation (10):

$$
\begin{aligned}
& \theta_{l}(t)=\theta_{l_{-} i}+ \\
& \Delta T\left(1-\frac{e^{-\xi_{l} \omega_{0 l} t}}{\sqrt{1-\xi_{l}^{2}}} \sin \left(\omega_{0 l} t \sqrt{1-\xi_{l}^{2}}+\cos ^{-1}\left(\xi_{l}\right)\right)\right)
\end{aligned}
$$

It is possible to consider that the high speed rotor is not influenced by a small step disturbance. With this hypothesis, the load angle evolution is proportional to the low speed rotor angle (this hypothesis will be confirmed thereafter by simulation). The evolution of the magnetic torque is given by (11). To determine the maximal amplitude of the torque wave, the evaluation of the overshoot of the load angle is necessary. It is given in \% by (12). The maximal amplitude of the torque wave can be then obtained by (13).

$$
\begin{gathered}
T_{l}(t)=T_{G} \cdot \sin \left(p_{l} \cdot \theta_{l}(t)+p_{h} \cdot \theta_{h_{-} i}\right) \\
O S_{\varphi}=100 \cdot e^{\frac{-\pi \xi_{l}}{\sqrt{1-\xi_{l}^{2}}}} \\
\Delta T_{l}=T_{G} \sin \left(\varphi_{\mathrm{i}}+\left(\varphi_{0}-\varphi_{\mathrm{i}}\right) O S_{\varphi}\right)-T_{G} \sin \left(\varphi_{\mathrm{i}}\right)
\end{gathered}
$$

Even if this expression is available for small disturbance, it represents correctly the behaviour of the magnetic gear for bigger disturbance (this result is confirmed by simulation). Moreover, this expression highlights that a disturbance has a direct consequence on the magnetic torque and can produce an uncoupling between the two rotors.

\section{Case where the damping factor is higher than one}

In the case where $\xi_{l} \geq 1$, the evolution of the position of low speed rotor $\left(\theta_{l}\right)$ can be described by equation (14). With the same hypothesis as in the last case, the new expression of the low speed rotor torque can be proposed in (15): 


$$
\left\{\begin{array}{c}
\theta_{l}(t)=\theta_{l_{-} i}+\Delta T\left(1+\frac{1}{\tau_{2}-\tau_{1}}\left(\tau_{1} e^{-t / \tau_{1}}-\tau_{2} e^{-t / \tau_{2}}\right)\right) \\
\tau_{1}=\omega_{0 l}\left(-\xi_{l}-\sqrt{\xi_{l}^{2}-1}\right) \\
\tau_{2}=\omega_{0 l}\left(-\xi_{l}+\sqrt{\xi_{l}^{2}-1}\right) \\
T_{l}(t)=T_{G} \cdot \sin \left(p_{l} \cdot \theta_{l}(t)+p_{h} \cdot \theta_{h_{-} i}\right)
\end{array}\right.
$$

In that case, the magnetic torque will not overshoot the amplitude of the disturbance. Considering the studied system, this result makes the system more robust to disturbances. Indeed, if there is no overshoot, it will be more difficult for the magnetic torque to reach the maximum gear torque value and create uncoupling between the two rotors.

\section{Conclusion for the two cases}

The present study highlights the different types of dynamic behaviour when magnetic gear is submitted to a step disturbance. It appears that in order to avoid an excessive magnetic torque peak (which could cause an overload in function of the safety margin), the case where the damping factor is higher than one is preferred.

To have a magnetic gear with a high torque density and a high efficiency, it is similar to minimize the damping factor (according to equation (8)) and the magnetic gear is likely to be in the case where the damping factor is less than one. To avoid any problem like uncoupling between rotors in this case, it will then transfer power with a nominal torque lower than the maximum gear torque to compensate the disturbance.

Considering the nonlinear equation to be solved in order to know the evolution of the magnetic torque for large displacement (equation (5)), simulations are performed to describe more precisely the magnetic gear behaviour and validate the previous hypothesis.

In the next section of this article, the dynamic study of a magnetic gear designed for wind power 3.9 MW, $15 \mathrm{rpm}$ (corresponding to the case where $\xi_{l} \geq 1$ ) will be presented. It is possible to carry out the same study for the other case ( $\xi_{l} \leq$ 1) with the same protocol as the one presented below.

\section{SimUlations OF THE MAGNETIC GEAR BEHAVIOUR WITH THE NONLINEAR MODELS}

In order to validate the analytical expressions established previously, it is possible to simulate the nonlinear behaviour of the magnetic gear. To do this, a block diagram is proposed in Fig. 6 where the input torque is imposed and the output speed is imposed. The simulation is performed for a magnetic gear designed for a wind turbine 3.9 MW, $15 \mathrm{rpm}$. Magnetic gear is obtained with an optimization described in [13] and dynamic parameters are defined in Table I.

In this part, the dynamic behaviour of the magnetic gear is evaluated with a step torque disturbance, a sinusoidal torque disturbance and a representative wind turbine torque disturbance.
TABLE I

PARAMETERS OF THE MAGNETIC GEAR

\begin{tabular}{|c|c|c|}
\hline Symbol & Quantity & Value \\
\hline$P_{\text {nom }}$ & Nominal power & $3.9 \mathrm{MW}$ \\
\hline $\mathrm{N}_{l}$ & Speed of high speed rotor & $15 \mathrm{rpm}$ \\
\hline$T_{\text {nom }}$ & Nominal torque & $2.5 \mathrm{MNm}$ \\
\hline$T_{G}$ & Maximum gear torque & $2.7 \mathrm{MNm}$ \\
\hline$G_{r}$ & Gear ratio (absolute value) & 6.5 \\
\hline$p_{h}$ & $\begin{array}{c}\text { Number of magnetic pole pairs } \\
\text { of high speed rotor }\end{array}$ & 20 \\
\hline$p_{l}$ & $\begin{array}{c}\text { Number of magnetic pole pairs } \\
\text { of low speed rotor }\end{array}$ & 130 \\
\hline$D_{e x t}$ & External diameter & $4 \mathrm{~m}$ \\
\hline$J_{h}$ & Inertia of high speed rotor & $1.010^{5} \mathrm{~kg} . \mathrm{m}^{2}$ \\
\hline$J_{l}$ & Inertia of low speed rotor & $1.210^{5} \mathrm{~kg} \cdot \mathrm{m}^{2}$ \\
\hline$f_{h}$ & $\begin{array}{c}\text { Fluid friction of the high speed } \\
\text { rotor }\end{array}$ & $3.710^{2} \mathrm{Nm} / \mathrm{rad} / \mathrm{s}$ \\
\hline$f_{l}$ & $\begin{array}{c}\text { Fluid friction of the low speed } \\
\text { rotor }\end{array}$ & $1.610^{4} \mathrm{Nm} / \mathrm{rad} / \mathrm{s}$ \\
\hline
\end{tabular}

\section{A. Behaviour of the magnetic gear with a step torque} disturbance.

For the first part of the study, the behaviour of the magnetic gear is evaluated with a step torque disturbance (16) and a maximum gear torque equal to $2.7 \mathrm{MN}$.m. This disturbance happens when the magnetic gear is stabilized in its nominal working point. Fig. 4 and Fig. 5 show the evolution of the magnetic torque on low speed rotor for the magnetic gear described in Table I and the step disturbance described above.

$$
\Delta T=\frac{3 \cdot T_{G}}{100}
$$

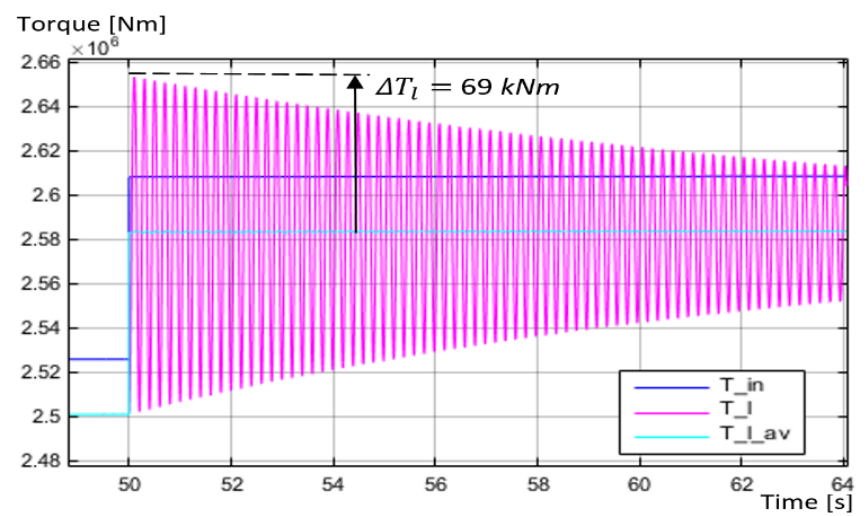

Fig.4 Evolution of low speed rotor torque with the step disturbance (16) and with a torque overshoot on the low speed rotor equal to $69 \mathrm{kN} . \mathrm{m}$.

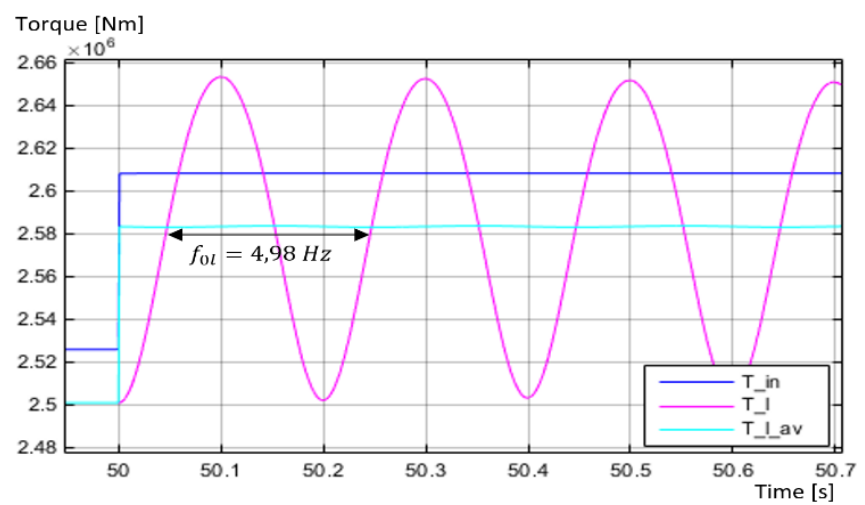

Fig. 5 Determination of the undamped resonance frequency of low speed rotor $(4.98 \mathrm{~Hz})$ corresponding to the step disturbance (16). 


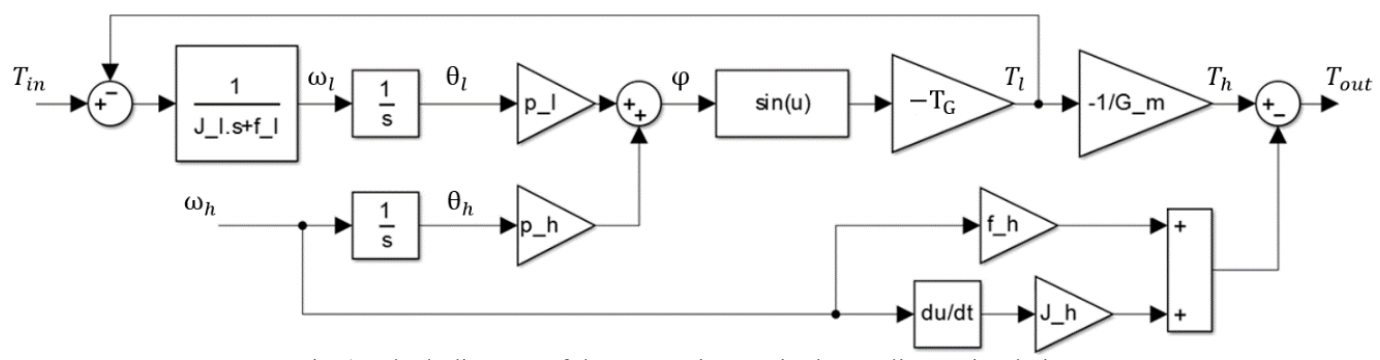

Fig.6 Block diagram of the magnetic gear in the nonlinear simulations

For the same parameters, the analytical expression gives results described in (17). Even if the analytical values are obtained with a Taylor expansion, they are very close to those obtained with nonlinear simulation. Such result validates the analytical expression.

$$
\left\{\begin{array}{l}
f_{0 l}=4,85 \mathrm{~Hz} \\
\Delta T_{l}=64 \mathrm{kNm}
\end{array}\right.
$$

For bigger step torque disturbance, analytical expression gives results close to results obtained with simulations. Then, a comparison can be made for different torque step disturbances with an initial torque equal to $0.8^{*} T_{G}(2.3 \mathrm{MN} . \mathrm{m})$. For bigger step torque disturbance, analytical expression gives expected results and can describe correctly the behaviour of the magnetic gear as shown in Table II.

TABLE II

RESULTS OF SIMULATIONS AND NUMERICAL VALUES FOR DIFFERENT STEP DISTURBANCE WITH AN INITIAL TORQUE EQUAL TO 2.3 MNM

\begin{tabular}{|c|c|c|}
\hline$\Delta T$ & $\begin{array}{c}\text { Simulation (torque in } \\
\mathrm{kN} . \mathrm{m} \text { and frequency in } \\
\mathrm{Hz} \text { ) }\end{array}$ & $\begin{array}{c}\text { Analytical expression } \\
\text { (torque in } \mathrm{kN} . \mathrm{m} \text { and } \\
\text { frequency in Hz) }\end{array}$ \\
\hline $3 \% . T_{G}$ & $\Delta T_{l}=81 f_{0 l}=6.77$ & $\Delta T_{l}=80 f_{0 l}=6.64$ \\
\hline $5 \% . T_{G}$ & $\Delta T_{l}=131 f_{0 l}=6.58$ & $\Delta T_{l}=125 f_{0 l}=6.46$ \\
\hline $8 \% . T_{G}$ & $\Delta T_{l}=188 f_{0 l}=6.25$ & $\Delta T_{l}=175 f_{0 l}=6.15$ \\
\hline $12 \% . T_{G}$ & $\Delta T_{l}=227 f_{0 l}=5.56$ & $\Delta T_{l}=193 f_{0 l}=5.59$ \\
\hline
\end{tabular}

\section{B. Stability of the magnetic gear}

Following different simulations of the behaviour of the magnetic gear with step torque disturbance, it is observed that a load angle value higher than $\pi / 2$ can be reached without uncoupling between the two rotors except during a transitory phase as shown in Fig. 7 and Fig. 8. Then, the operating range of a magnetic gear can be increased during the transitory phase or when a magnetic gear is installed in an application with disturbances.

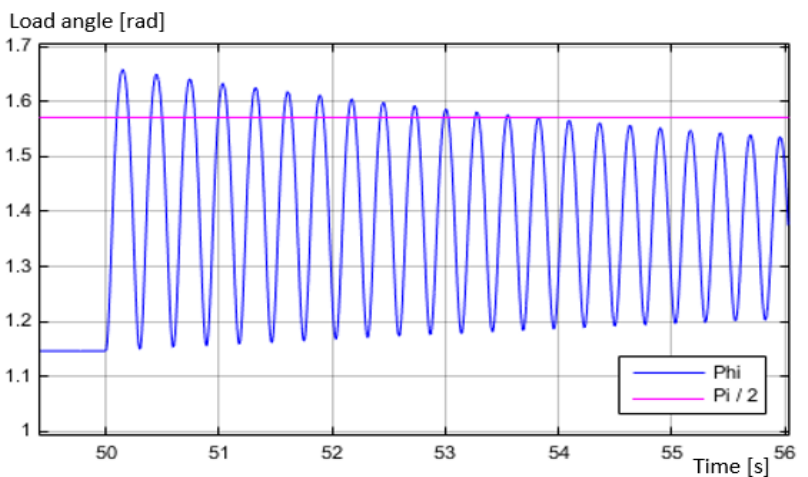

Fig.7 Evolution of the load angle with a step disturbance who generates a load angle value higher than $\pi / 2$ without uncoupling between two rotors.

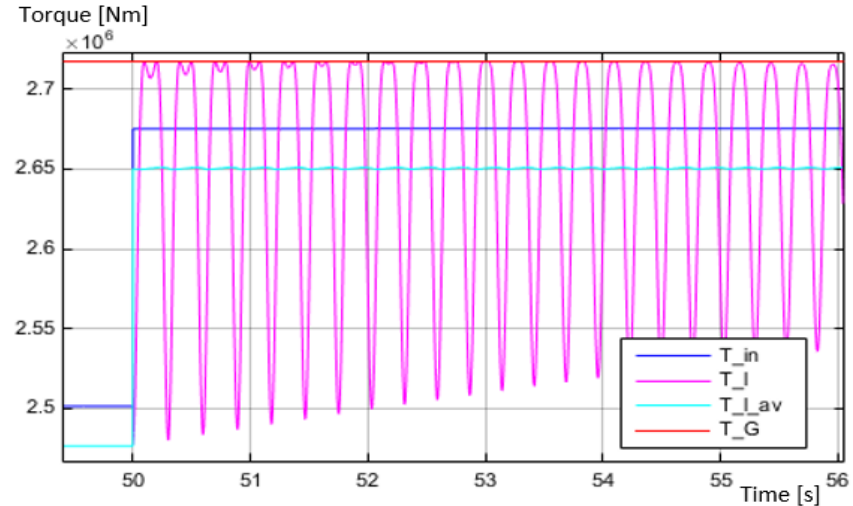

Fig. 8 Evolution of the magnetic torque on a low speed rotor with a step disturbance which generates a load angle value higher than $\pi / 2$ without uncoupling between two rotors $\left(T_{G}=2.73 \mathrm{MN} . \mathrm{m}\right)$.

According to the result and for magnetic gear characterized in Table I with a step torque disturbance, it is possible to define dynamic limit of stability without uncoupling between the two rotors in function of the initial torque (before step torque disturbance) and $\Delta T$, see Fig. 9.

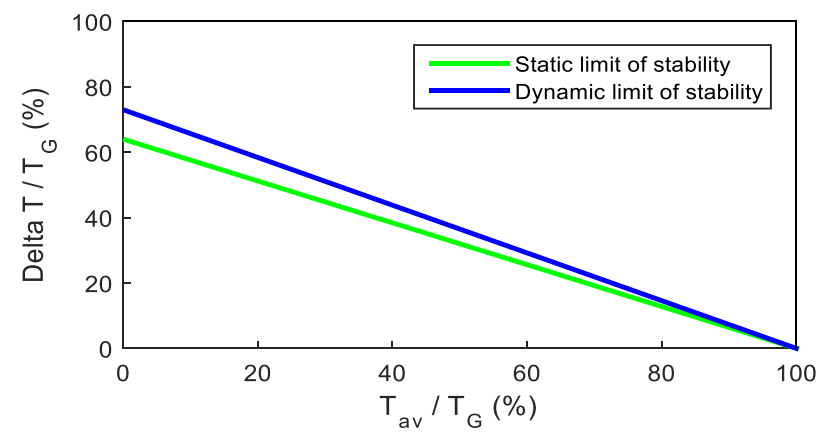

Fig.9 Dynamic and static limit of stability without uncoupling between rotors for a torque step disturbance $\left(T_{G}=2.73 \mathrm{MN} . \mathrm{m}\right)$.

If the torque disturbance can be represented with a sinusoid instead of a step, operating range could be defined in function of the average torque $T_{a v}$, the amplitude and the frequency of the sinusoid respectively $\Delta T$ and $f_{\text {dist }}$ (Fig. 10-12) with an input torque proposed in (18). Fig. 10-12 illustrate that the operating range is reduced when the frequency of the sinusoid is close enough to the resonance frequency of the low speed rotor. Indeed, in regard of the equation (8), the resonance frequency of the low speed rotor depends on the average torque and evolves like (19).

$$
T_{i n}(t)=T_{G}\left(\frac{T_{a v}}{T_{G}}+\frac{\Delta T}{T_{G}} \sin \left(2 \pi . f_{\text {dist }} . t\right)\right)
$$




$$
\left\{\begin{array}{l}
\frac{10 . T_{G}}{100} \leq T_{a v} \leq \frac{90 . T_{G}}{100} \\
8.6 \mathrm{~Hz} \geq f_{0 l} \geq 5.5 \mathrm{~Hz}
\end{array}\right.
$$

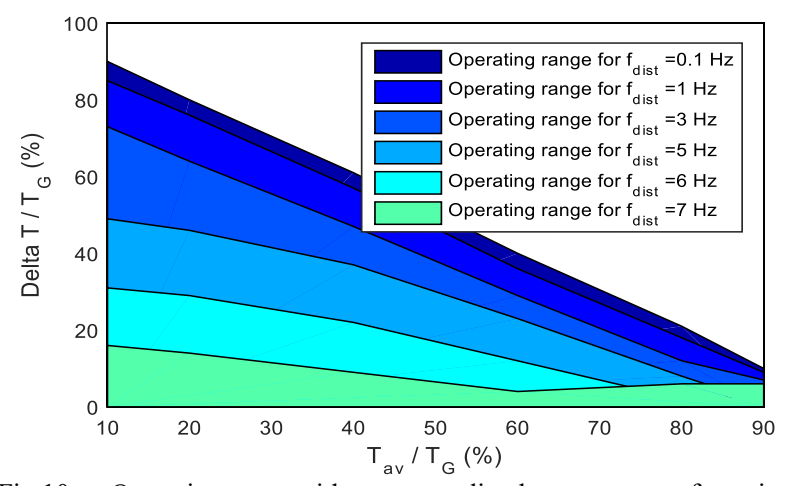

Fig.10 Operating range without uncoupling between rotors for a sinusoidal torque disturbance with frequency up to $7 \mathrm{~Hz}\left(T_{G}=2.73 \mathrm{MN} . \mathrm{m}\right)$.

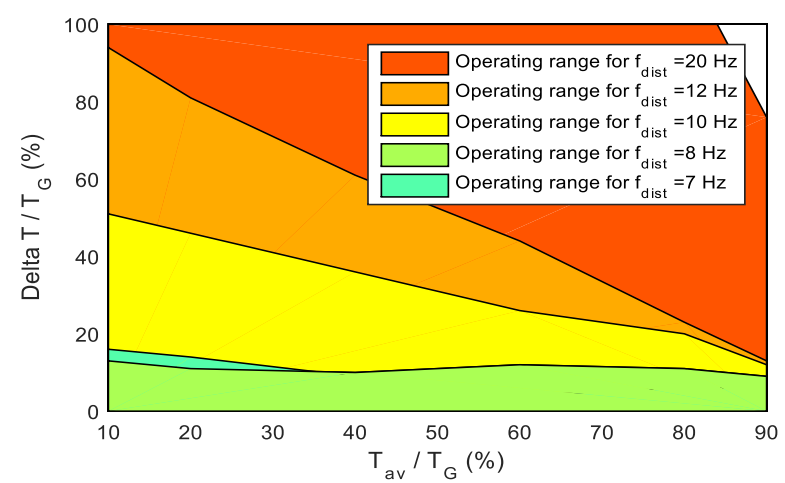

Fig.11 Operating range without uncoupling between rotors for a sinusoidal torque disturbance with frequency from $7 \mathrm{~Hz}$ to $20 \mathrm{~Hz}\left(T_{G}=2.73 \mathrm{MN} . \mathrm{m}\right)$.

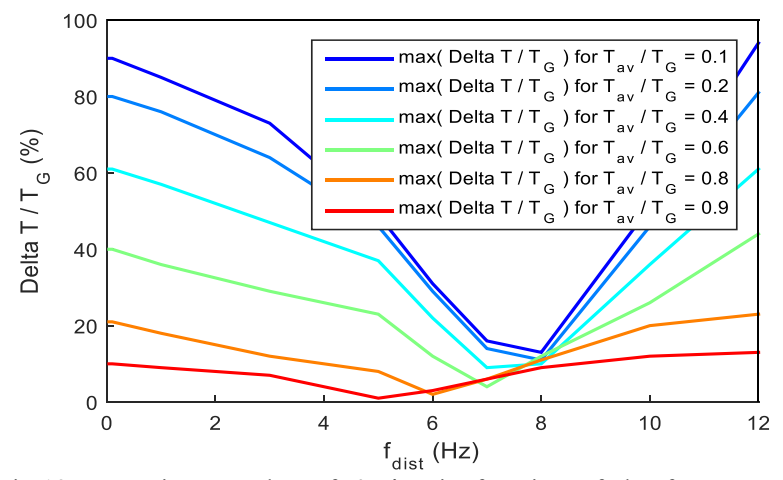

Fig.12 Maximum value of $\Delta T / T_{G}$ in function of the frequency of the disturbance without uncoupling between rotors for different value of $T_{a v} / T_{G}$ $\left(T_{G}=2.73\right.$ MN.m).

\section{Behaviour simulation of the magnetic gear with wind turbine disturbance}

The previous results are independent of the application field. This section will focus on a wind turbine application with conversion chains proposed in Fig. 1c. Input torque of the magnetic gear follows (20):

$$
\begin{aligned}
& T_{\text {in }}(t)=T_{\text {nom }}\left(1+\frac{5}{100} \sin \left(3 \theta_{l}(t)\right)+\frac{0.3}{100} \sin (0,10 t)\right. \\
& \left.+\frac{3}{100} \sin (0,27 t)+\frac{1}{100} \sin (1,29 t)+\frac{0.3}{100} \sin (3,66 t)\right)
\end{aligned}
$$

In this expression, the first term corresponds to the nominal torque, the second term corresponds to the influence of passage of the blades in front of the tower for a three blades wind turbine. The other terms correspond to typical wind fluctuations.

With a mechanical torque on the input of the magnetic gear following (20), it is not possible to have a nominal torque too close to the maximal gear torque. Also, to maintain a high torque density of the magnetic gear, the ratio between nominal torque and maximum gear torque (21) must be maximized. With this load, iterative simulations are performed; the maximum value of the ratio is $\mathrm{k}=92.5 \%$. Fig. $13-14$ illustrate the evolution of the torque and the load angle with this value.

$$
k=\frac{T_{n o m}}{T_{G}}
$$

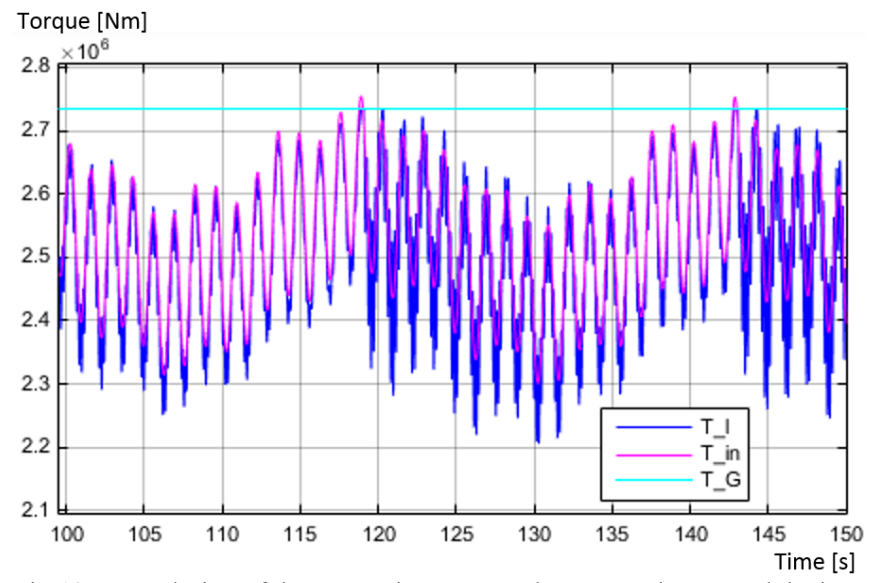

Fig.13 Evolution of the magnetic torque on low a speed rotor and the input torque of the magnetic gear with $\mathrm{k}=92.5 \%$ and the load described in $(20)\left(T_{G}\right.$ $=2.73 \mathrm{MN} . \mathrm{m}$ and $T_{\text {nom }}=2.5 \mathrm{MN} . \mathrm{m}$ ).

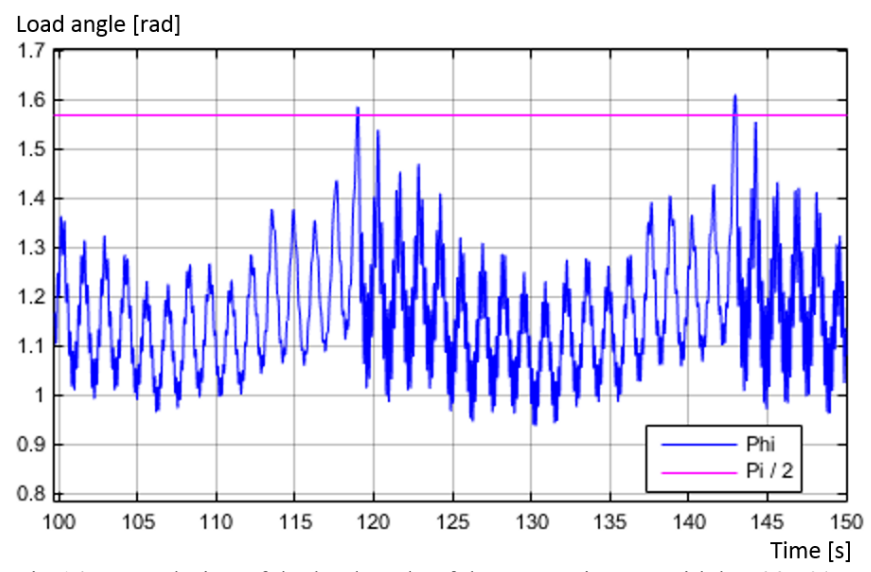

Fig.14 Evolution of the load angle of the magnetic gear with $\mathrm{k}=92.5 \%$ and the load described in (20) $\left(T_{G}=2.73 \mathrm{MN} \cdot \mathrm{m}\right.$ and $\left.T_{\text {nom }}=2.5 \mathrm{MN} \cdot \mathrm{m}\right)$.

\section{CONCLUSION}

This article brings several contribution to the modelling of magnetic gear:

A. An analytical expression has been proposed for small torque step disturbance on magnetic gear. Because of the nonlinearity of the equation, the analytical expression does not seem valid for bigger step disturbance. However, simulations have permitted to observe that the analytical expression describes with good agreement the magnetic gear behaviour for bigger disturbance. In function of the geometry of the magnetic gear, the damping factor can be small and the 
overshoot torque expression can be simplified, as shown in equation (22):

$$
\left\{\begin{array}{c}
\theta_{l}(t)=\theta_{l_{-} i}+\Delta T\left(1-e^{-\xi_{l} \omega_{0 l} t} \cdot \sin \left(\omega_{0 l} \cdot t+\frac{\pi}{2}\right)\right) \\
T_{l}(t)=T_{G} \cdot \sin \left(p_{l} \cdot \theta_{l}(t)+p_{h} \cdot \theta_{h i}\right)
\end{array}\right.
$$

B. It is possible to define an operating range of magnetic gear in function of the average torque and the amplitude of the disturbance. For sinusoidal torque disturbance with the frequency lower than the resonance frequency of the low speed rotor, the operating range is similar than the operating range with a step disturbance. The operating range is strongly reduced for frequency similar than the resonance frequency of the low speed rotor as shown in Fig. 10. Given that the magnetic gear behavior is similar than a low pass filter, magnetic gear allow sinusoidal torque disturbance with frequency higher than there resonance frequency of the low speed rotor (Fig. 11).

C. Another important observation is the necessity to have a nominal torque away from the maximal gear torque in function of the application typical disturbance is planned to be integrated a magnetic gear. For wind power application, with the input torque described in equation (18), the maximal ratio between the nominal torque and the maximal gear torque is equal to $92.5 \%$.

$D$. The last observation corresponds to load angle value higher than $\pi / 2$ without uncoupling between the two rotors during a transitory phase. This result permits to increase the operating range of the magnetic gear when the magnetic gear is integrated in an application with lot of disturbances.

In order to improve the dynamic behaviour analysis of the magnetic gear, it could be interesting to develop an analytical model of the induced current loose. The damping factors will be different and the coupling between the two rotors of the magnetic gear could be more robust. On the other hand, the different dynamic criteria developed in this article will be used in a future mechatronic optimization of this magnetic gear.

\section{ACKNOWLEDGMENT}

The authors would like to thank Jeumont Electric for the different discussions around the system design and more particularly D. Laloy, D. Ekeom and A. Fasquelle.

\section{REFERENCES}

[1] F. Spinato, P. Tavner, G. Van Bussel, " Reliability of wind turbine subassemblies ", IET Renewable Power Generation, Vol. 3, Iss.4, 2009

[2] K. Atallah, and D. Howe, "A novel high-performance magnetic gear ", IEEE Trans. Magn., vol. 37, No. 4, pp. 2844-2846, July 2001

[3] K. Atallah, S.D. Calverley, D. Howe, «Design, Analysis and realization of a high-performance magnetic gear", IEE Proc.-Electr. Power Appl., Vol. 151, No. 2, March 2004

[4] P. O. Rasmussen, T. O. Andersen, F. T. Jorgensen, and O. Nielsen, "Development of a high-performance magnetic gear", IEEE Trans. Ind. Appl., vol. 41, No. 3, pp. 764-770, May/Jun. 2005.

[5] T. Lubin, S. Mezani, A. Rezzoug, "Analytical computation of magnetic field distribution in a magnetic gear ", IEEE Trans on magnetics, Vol. 46, No. 7, July 2010
[6] E. Gouda, S. Mezani, L. Baghli, A. Rezzoug, "Comparative study between mechanical and magnetic planetary gears", IEEE Trans on magnetics, Vol. 46, No. 2, Feb. 2011

[7] L. N. Jian, K. T. Chau, D. Zhang, J. Z. Jiang, and Z. Wang, "A magnetic geared outer-rotor permanent-magnet brushless machine for wind power generation", in Conf. Rec. 2007 IEEE 42nd IAS Annual Meeting Ind. Appl., Sep. 23-27, 2007, pp. 573-580

[8] N. W. Frank and H. A. Toliyat, "Gearing ratios of a magnetic gear for wind turbines",in Proc. IEEE Int. Elect. Mach. Drives Conf. (IEMDC), May 3-6, 2009, pp. 1224-1230.

[9] D. Matt, J. Jac, N. Ziegler, "Design of a Mean Power Wind Conversion Chain with a Magnetic Speed Multiplier",Advances in Wind Power, Chap 10 , INTECH, Nov. 2012

[10] A. Penzkofer, K. Atallah, "Magnetic Gears for High Torque Applications",IEEE Trans on magnetics, Vol. 50, No. 11, Nov. 2014

[11] R. G. Montague, C. M. Bingham,K. Atallah, "Magnetic gear overload detection and remedial strategies for servo-drive systems", SPEEDAM 2010

[12] R. G. Montague, C. M. Bingham,K. Atallah, "Servo Control of Magnetic Gears", IEEE Trans on mechatronics, Vol. 17, No. 2, Avril 2012

[13] M. Desvaux, R. Le Goff Latimier, B. Multon, H. Ben Ahmed, S. Sire, "Design and optimization of magnetic gears with arrangement and mechanical constraints for wind turbine applications ", Conf. Ecological Vehicles and Renewable Energies (EVER), 2016 Eleventh International Conference (pp. 1-8). IEEE. Accepted

\section{BIOGRAPHIES}

Melaine Desvaux received a B.S degree in electronics and telecommunication and a B.S degree in mechanical engineering, in 2012 and a M.S. degree in mechatronic design in 2015, from the University of Rennes 1, France. He passed the "Agregation" exam in Mechanical Engineering in 2014. He is currently pursuing a Ph.D. degree in mechatronic engineering at the SATIE Laboratory, ENS Rennes, France.

His research includes the integration of magnetic gears in wind power application which requires skills in automatic, vibration, optimization and magnetism domains.

Roman Le Goff Latimier received Agregation in Electrical Engineering in 2012. He received a M.S. degree in renewable energy in 2013, from Ecole Polytechnique, France. He is pursuing the Ph.D. degree in electrical engineering at the SATIE Laboratory, ENS Rennes, France, on the optimal sizing and management of renewable sources and electric vehicle fleets.

His research interest includes among others stochastic optimization energy forecasting smart grids with large penetration of stochastic and distributed agents.

Bernard Multon received the M.S. degree in electrical engineering from the Ecole Normale Supérieure de Cachan, France, in 1981, Electrical Engineering Agrégation in 1982 and the Ph.D. degree from the University of Paris 6, in 1985. From 1988 and 1995, he was Assistant Professor in the Electrical Engineering Department, ENS Cachan, and Leader of the Research Special Actuator Design Group in LESiR-CNRS. Since 1995, he is Full Professor in ENS Rennes and he teaches in the Mechatronics Department.

His research is in the SETE team of laboratory SATIE-CNRS. It concerns sizing of electromechanical chain and sizing and management of renewable electrical energy conversion systems on their overall life cycle.

Stephane Sire received the PhD degree in mechanical engineering in 2002 from Ecole Centrale Nantes, France. Since 2005, he is an Assistant Professor at the University of Brest, France.

His research topics include the mechanical behaviour of assemblies and structures (experimental characterization and modelling).

Hamid Ben Ahmed received the PhD degree and HDR degree in 1994, and 2006 respectively. From 1994 to 1997, he was a Research Associate in the SATIE laboratory. Since 1997, he is an Assistant Professor in the Mechatronic Department of ENS Cachan, France (which became ENS Rennes).

His research interest includes the design, modelling and optimization of novel topologies of electromagnetic actuators and generators, and the optimization of renewable energy systems. 